MATEC Web of Conferences 3, 01041 (2013)

DOI: $10.1051 /$ matecconf/20130301041

(C) Owned by the authors, published by EDP Sciences, 2013

\title{
Vapor-liquid equilibrium data concerning refrigerant systems (R3110+R365mfc)
}

\author{
H. Madani ${ }^{1}$, A. Valtz ${ }^{2}$, and C. Coquelet ${ }^{2}$ \\ ${ }^{1}$ Laboratoire d'étude des systèmes Energétiques Industriels, Université de Batna, Algérie \\ ${ }^{2}$ MINES ParisTech (CEP-TEP), Centre énergétique et procédés, 35 Rue Saint Honoré, 77305 Fontainebleau, France
}

In ORC, the knowledge of phase diagram of working fluid is essential. In this paper isothermal vapor liquid equilibrium data are presented for the R3310 + R365mfc system. Measurement were performed for seven isotherms (three below and four above the critical temperature of $\mathrm{C}_{4} \mathrm{~F}_{10}$ ) ranging from 333.26 to $441.61 \mathrm{~K}$, with pressure ranging from 0.2016 to $3.0927 \mathrm{MPa}$. The measurements were undertaken using a "static-analytic" type apparatus, with sampling of the equilibrium phases via capillary samples $\left(\mathrm{ROLSI}^{\mathrm{TM}}\right)$. The maximum uncertainties in the measurements were within $\pm 0.02 \mathrm{~K}$, $0.0003 \mathrm{MPa}$ and less than \pm 0.004 for temperature, pressure, and equilibrium phase mole fractions, respectively. The full set of isothermal vapor-liquid equilibrium data were correlated with the Peng-Robinson equation of state, incorporating the Mathias-Copeman alpha function, with the Wong-Sandler mixing rule utilizing the NRTL activity coefficient model. 